medRxiv preprint doi: https://doi.org/10.1101/2021.04.27.21252790; this version posted April 29, 2021. The copyright holder for this preprint

(which was not certified by peer review) is the author/funder, who has granted medRxiv a license to display the preprint in perpetuity.

All rights reserved. No reuse allowed without permission.

\title{
SARS-CoV-2 Vaccination Uptake in a Correctional Setting
}

Justin Berk, MD, MPH, MBA*

Medical Director, Rhode Island Department of Corrections

Assistant Professor, Warren Alpert School of Medicine at Brown University

Matthew Murphy, MD, MPH

Assistant Professor, Warren Alpert School of Medicine at Brown University

Philip A. Chan, MD, MS

Consultant Medical Director, Rhode Island Department of Health

Associate Professor, Warren Alpert School of Medicine at Brown University

Kimberly Kane, APRN-BC

Director of Nursing, Rhode Island Department of Corrections

Jody Rich, MD MPH

Director, The Center for Health and Justice Transformation

Professor, Warren Alpert School of Medicine at Brown University

Lauren Brinkley-Rubinstein, $\mathrm{PhD}$

Assistant Professor, University of North Carolina at Chapel Hill School of Medicine

*Corresponding author

245 Chapman St, Ste 100

Providence, RI 02905

justin_berk@brown.edu | (t) 401-444-6118

The authors (JB, MM, PC, KK, JR, LBR) have no financial disclosures or conflicts of interest.

Word Count: 1120

\begin{abstract}
Between December 2020 and February 2021, the Rhode Island Department of Corrections offered SARSCoV-2 vaccination to all correctional staff and sentenced individuals incarcerated in the state. During this initial campaign, 76.4\% (1106/ 1447) of sentenced individuals and 68.4\% (1008 / 1474) of correctional staff accepted and received the vaccine. This study demonstrates the feasibility and efficiency of vaccine implementation in a carceral setting.
\end{abstract}


medRxiv preprint doi: https://doi.org/10.1101/2021.04.27.21252790; this version posted April 29, 2021. The copyright holder for this preprint

(which was not certified by peer review) is the author/funder, who has granted medRxiv a license to display the preprint in perpetuity.

All rights reserved. No reuse allowed without permission.

\section{Introduction}

The largest outbreaks of COVID-19 in the United States have occurred in correctional facilities. ${ }^{1}$ Correctional outbreaks have substantially contributed to community and statewide spread of infection. ${ }^{2}$ The rate of COVID-19 in correctional settings is five times that of the general population, and the ageadjusted mortality rate is nearly four times higher. ${ }^{3}$ Thus, vaccinating individuals who live and work in correctional facilities should be a high priority and is recommended by multiple organizations. ${ }^{4,5}$ Despite these recommendations, few states initially prioritized vaccination in correctional settings. ${ }^{6}$ Furthermore, vaccine uptake among correctional staff and incarcerated individuals is unknown.

The goal of the current study was to evaluate the rate of vaccine uptake among staff and incarcerated individuals at the Rhode Island Department of Corrections (RIDOC), the first statewide correctional system to offer vaccine to all sentenced individuals in February 2021.

\section{Methods}

From the beginning of the pandemic, RIDOC collaborated closely with the Rhode Island Department of Health on addressing COVID-19 with aggressive testing and isolation procedures, mask wearing, surface sanitation, and ongoing education of staff and incarcerated individuals.

SARS-CoV-2 vaccines were initially offered starting on December 22, 2020 and first-dose administrations were completed on February 5, 2021. All second-dose vaccinations were completed by March 5, 2021. The RIDOC is a unified (combined prison and jail) statewide correctional facility that houses approximately 1,500 sentenced and 500 awaiting-trial individuals across six security facilities. The vaccine program focused on incarcerated people who had received a sentence after a criminal trial. This includes individuals typically housed in prisons. Staff (e.g., correctional officers) were concurrently vaccinated at the RIDOC through a parallel vaccine program.

Among incarcerated people, a general system of "Rounds" prioritized vaccine allocation based on risk factors and/or security facility. All eligible individuals were offered vaccine on an opt-out basis. RIDOC nurses administered the vaccine. Two RIDOC public health nurses provided education on the vaccine and consent before the vaccine clinic day. Second doses were provided at appropriate time intervals.

In Phase 1, "highest-risk" individuals (age over 65 years old or over 55 years old with specific comorbidities) were offered vaccine. In Phase 2 , smaller facilities were offered vaccine in attempt to achieve herd immunity in those communities. Phase 3 included the largest remaining security facility: Medium Security. Phase 4 included all individuals who had previously tested positive for COVID-19 within 90 days and individuals who had initially declined but subsequently accepted. After completion of the 4 phases, vaccines continued to be offered by request and coordination with the local Department of Health.

Among corrections staff, individuals were vaccinated with an opt-in system, prioritizing high-risk correctional officers and individuals with direct contact with incarcerated people. Vaccine education was provided during morning "roll call" and an educational video was created by the Medical Director and made available on the intranet. Additional information regarding vaccine education and resources was sent via email to the entire RIDOC department.

\section{Results}

During the six-week campaign, a total of 1,106 incarcerated individuals and 1,008 staff received the vaccine, $76.4 \%$ and $68.4 \%$ of the populations, respectively. (For comparison, the rate of influenza vaccination uptake at the RIDOC last year was 50.6\%.) Table 1 describes the four phases of first-dose vaccination. Among Round 1 "highest-risk" recipients, approximately $9.1 \%$ declined the offer of vaccine. Among Round 2 individuals, rates of decline varied by security facility but were between $25 \%$ and $40 \%$ with an overall refusal rate of $35.6 \%$. Round 3 included mostly individuals at the facility with the highest number of previous COVID-19 cases (Medium Security); the refusal rate was 17.1\%. Round 4 rates of refusal were approximately 35\%. Among staff, 1,008 employees or contractors received vaccine. A total of 466 of 1,474 individuals (31\%) did not opt-in for the initial vaccine offering. 
medRxiv preprint doi: https://doi.org/10.1101/2021.04.27.21252790; this version posted April 29, 2021. The copyright holder for this preprint

(which was not certified by peer review) is the author/funder, who has granted medRxiv a license to display the preprint in perpetuity.

All rights reserved. No reuse allowed without permission.

Second-dose vaccines were administered approximately 28 days after the original dose. Due to logistics, some doses were delayed by $1-2$ weeks due to vaccine delivery times and staffing availability. Three incarcerated individuals and six staff members who received their first dose of vaccine opted to not receive their second dose. During this time "over-pulls" and additional vaccine clinics were offered to incarcerated individuals and staff that ultimately did opt-in to receive vaccine on a rolling basis based on vaccine availability.

Four months after the first vaccine was offered on $12 / 22 / 20,77.7 \%$ of the sentenced population was fully vaccinated and $69.6 \%$ of staff were fully vaccinated. At the time, $37.6 \%$ of the patient population at the Intake facility is vaccinated, though this is a transient population that is constantly changing. Future vaccination efforts for this population are planned to be single-dose vaccines. There were no significant vaccine adverse events.

\section{Discussion}

Vaccination was efficient with a high acceptance rate of $70 \%-75 \%$ among both staff and incarcerated people. This aligns with necessary immunization rates modeled to achieve herd immunity ${ }^{7}$ and is a departure from some concerns of high vaccine hesitancy rates including a recent CDC publication estimating a $45 \%$ willingness to receive vaccine among incarcerated people. ${ }^{8}$ Education and communication likely played an important role in mitigating refusals; efforts to increase vaccine uptake will continue. To our knowledge, the RIDOC is the first statewide correctional system to have offered SARS-CoV-2 vaccination to all sentenced individuals and staff.

The high acceptance rate in a correctional setting is particularly relevant given the increased risk of Covid-19-related transmission, disease, and death in this population. ${ }^{3}$ The pandemic has devastated correctional settings and the spread of disease in these facilities can catalyze transmission to their surrounding communities. ${ }^{2}$ Similarly, as Covid-19 has disproportionately affected communities of color, so too has rates of incarceration. ${ }^{9}$ Thus, by vaccinating incarcerated people, policymakers can target a high-risk and marginalized group, decrease community spread, improve equitable allocation to a marginalized group, and potentially reduce the health system costs of neighboring health systems. The successful vaccination of incarcerated individuals and staff in the state of Rhode Island demonstrates the feasibility and efficiency of widespread vaccine programming among those at high risk.

Vaccination of incarcerated people does have unique challenges. Rhode Island was able to coordinate the administration of second doses among the sentenced population without loss to follow up, but this was in part due to the small size of the state's population. Additionally, the jail setting offers a greater challenge given the high turnover of the population often with individuals being released to the community before their second dose is due. The strategic implementation of single-dose vaccine may align with this unique environment going forward.

The success of this vaccination campaign exemplifies the importance of adherence to public health principles: vaccinate where spread and disease can best be prevented. Correctional settings should remain a priority in vaccination strategies during a pandemic and indeed offers an opportunity to target a high-risk, marginalized, and difficult-to-reach populations. 
medRxiv preprint doi: https://doi.org/10.1101/2021.04.27.21252790; this version posted April 29, 2021. The copyright holder for this preprint (which was not certified by peer review) is the author/funder, who has granted medRxiv a license to display the preprint in perpetuity.

All rights reserved. No reuse allowed without permission.

Table 1. First-Dose SARS-CoV-2 Vaccination of Incarcerated People and Correctional Staff

\begin{tabular}{|c|c|c|c|c|c|c|}
\hline Round & Group Description & Dates & Offered & Vaccinated & Declined & $\begin{array}{l}\text { Decline } \\
\text { Rate }\end{array}$ \\
\hline 1 & $\begin{array}{l}\text { Age }>64, \\
\text { Immunocompromised, or } \\
\text { Age }>54 \text { with co-morbidities }\end{array}$ & $\begin{array}{l}12 / 26 / 20- \\
12 / 29 / 20\end{array}$ & 143 & 130 & 13 & $9.1 \%$ \\
\hline 2 & $\begin{array}{l}\text { Small Facilities (Minimum, } \\
\text { Maximum, High, Women's) }\end{array}$ & $\begin{array}{l}12 / 31 / 20- \\
1 / 5 / 21\end{array}$ & 222 & 143 & 79 & $35.6 \%$ \\
\hline 3 & $\begin{array}{l}\text { Medium and Sentenced } \\
\text { Individuals Awaiting } \\
\text { Transfer }\end{array}$ & $\begin{array}{l}1 / 13 / 21- \\
1 / 27 / 21\end{array}$ & 730 & 605 & 125 & $17.1 \%$ \\
\hline 4 & $\begin{array}{l}\text { All Remaining Sentenced, } \\
\text { including those who had } \\
\text { COVID-19 within } 90 \text { days }\end{array}$ & $\begin{array}{l}1 / 29 / 21- \\
2 / 5 / 21\end{array}$ & 352 & 228 & 124 & $35.2 \%$ \\
\hline \multicolumn{3}{|c|}{ INCARCERATED PEOPLE TOTALS } & 1,447 & 1,106 & 341 & $23.6 \%$ \\
\hline \multicolumn{7}{|c|}{ SARS-CoV-2 Vaccination of Correctional Officers and Other Staff } \\
\hline $\begin{array}{l}\text { Staff } \\
\text { Totals }\end{array}$ & $\begin{array}{l}\text { Priority to self-reported } \\
\text { high-risk individuals those } \\
\text { with direct contact of } \\
\text { incarcerated individuals }\end{array}$ & $\begin{array}{l}12 / 22 / 20- \\
2 / 10 / 21\end{array}$ & 1,474 & 1,008 & 466 & $31.6 \%$ \\
\hline
\end{tabular}

*A portion of Round 1 utilized the Pfizer vaccine, the rest utilized the Moderna vaccine.

Table 2. SARS-CoV-2 Vaccination of Incarcerated People and Correctional Staff (Four-Month Follow-up)

Facility Fully Vaccinated Total Population Vaccinated Rate

\begin{tabular}{|l|c|c|c|}
\hline Intake Facilities & 319 & 847 & $37.6 \%$ \\
\hline Sentenced Population & 1001 & 1289 & $77.7 \%$ \\
\hline Staff & 1027 & 1474 & $69.6 \%$ \\
\hline
\end{tabular}


medRxiv preprint doi: https://doi.org/10.1101/2021.04.27.21252790; this version posted April 29, 2021. The copyright holder for this preprint

(which was not certified by peer review) is the author/funder, who has granted medRxiv a license to display the preprint in perpetuity.

All rights reserved. No reuse allowed without permission.

\section{REFERENCES}

1. Macmadu A, Berk J, Kaplowitz E, Mercedes M, Rich JD, Brinkley-Rubinstein L. COVID-19 and mass incarceration: a call for urgent action. Lancet Public Heal. 2020;5(11):e571-e572. doi:10.1016/S2468-2667(20)30231-0

2. Reinhart E, Chen DL. Incarceration And Its Disseminations: COVID-19 Pandemic Lessons From Chicago's Cook County Jail. Health Aff (Millwood). 2020;39(8):1412-1418. doi:10.1377/hlthaff.2020.00652

3. Saloner B, Parish K, Ward JA, Dilaura G, Dolovich S. COVID-19 cases and deaths in federal and state prisons. JAMA - J Am Med Assoc. 2020;324(6):602-603. doi:10.1001/jama.2020.12528

4. Wang E, Brinkley-Rubinstein L, Puglisi L, Western B. Recommendations for Prioritization and Distribution of COVID-19 Vaccine in Prisons and Jails.; 2020. https://justicelab.columbia.edu/sites/default/files/content/COVID_Vaccine_White_Paper.pdf

5. Turcotte M, Sherman R, Norma D. Federal Judge Orders Oregon State Prisons to Vaccinate Inmates. New York Times. https://www.nytimes.com/2021/02/03/world/oregon-prison-inmatesvaccine.html. Published February 3, 2021. Accessed February 12, 2021.

6. The COVID Prison Project. COVID Vaccinations. Published 2021. Accessed February 12, 2021. https://covidprisonproject.com/covid-vaccination-new-divi/

7. Britton T, Ball F, Trapman P. A mathematical model reveals the influence of population heterogeneity on herd immunity to SARS-CoV-2. Science (80- ). 2020;369(6505):846-849. doi:10.1126/science.abc6810

8. Stern MF, Piasecki AM, Strick LB, et al. Willingness to Receive a COVID-19 Vaccination Among Incarcerated or Detained Persons in Correctional and Detention Facilities — Four States, September-December 2020. MMWR Morb Mortal Wkly Rep. 2021;70(13):473-477. doi:10.15585/mmwr.mm7013a3

9. Macmadu A, Berk J, Kaplowitz E, Mercedes M, Rich JD, Brinkley-Rubinstein L. COVID-19 and mass incarceration: a call for urgent action. Lancet Public Heal. 2020;5(11):e571-e572. doi:10.1016/S2468-2667(20)30231-0 